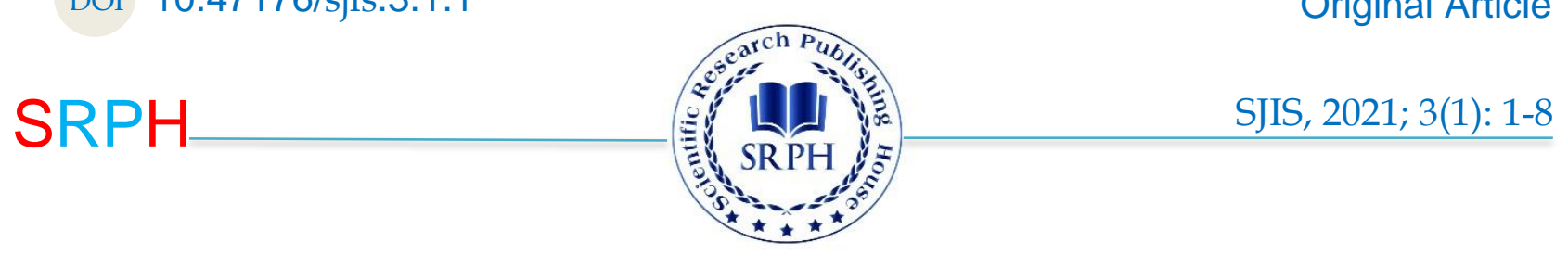

\title{
Stability Analysis of Mineral Structures using FLAC Software
}

\author{
Javad Vaze Mobaraki* \\ M.Sc. Graduated from Birjand \\ University, Iran.

\section{*Corresponding Author: \\ $>$ mobaraki@gmail.com}

Received: 15 October, 2020

Accepted: 15 January, 2021

Published: 30 January, 2021

\begin{abstract}
The safety factor for slopes (FS) is traditionally determined using two-dimensional limit equilibrium (LEM) methods, however, the safety factor of a slope can also be calculated by FLAC software with the technique of reducing soil shear strength in the time stages until the slope fails. In this presentation, we first describe the numerical methods of stability analysis, finite difference method and FLAC software, and then we analyze the static stability using FLAC software.
\end{abstract}

Keywords: Stability analysis, Numerical methods, Finite difference method, FLAC software

\section{Introduction}

The open-mining slope design is a deal between sustainability and the economy. The steeper the slope, the cheaper it is to build, because steeper slopes lead to lower utilization rates, in other words, the ratio of the ores to the ore. On the other hand, however, the more flat slope is more stable. Therefore, the purpose of any outdoor mine design is to provide optimal drilling configuration in the field of safety, ore recovery and financial returns. Based on the above, geotechnical engineering is an important part of any prestigious open-pit mine design [1].

Rock masses are the best description of batch, heterogeneous, non-isotropic and non-elastic materials. Different from materials produced in methods such as metals or plastics, physical properties and mass engineering of rocks cannot be easily defined or created. Therefore, the masses of rocks are complex materials for mathematical modeling in closed forms. And therefore, the use of numerical modeling to design and evaluate the engineering properties of stone becomes inevitable [2].

Traditional slope stability analysis includes predicting the critical slip surface position for a given slope and calculating the safety factor in that position. However, for some slopes with complex histology, several different critical slip surfaces can be available. Also, the minimum total safety factor in some samples can be less important than the areas of potential degradation when rehabilitation or strengthening a slope.

A wide range of methods have been developed to solve the problem of slope stability. Methods such as Limit equilibrium (LEM), Strenght reduction (SRM) and limited analysis method are commonly used. Limit equilibrium and Strenght reduction methods have been accepted by researchers and perpetrators in many cases. Both methods, although originally definitive, can be easily adapted to the probability models.

The Strenght Reduction Method (SRM) has been modified in several known finite element programs (PLAXIS, GEO5) or finite difference (FLAC). To perform stability analysis, SRM uses a 3D correlated solid background that is solved using finite element or finite difference methods. Suitable for this complex problem, both methods of partial equilibrium and reduction of resistance have their own advantages and disadvantages. The limit equilibrium method requires less detailed information about the location and in most samples provides satisfactory results when the water pressure is properly modeled. Because the partial equilibrium method is commonly used in most cases to evaluate slope stability in practice, extensive research has been accepted in an effort to improve its implementation method [3]. 


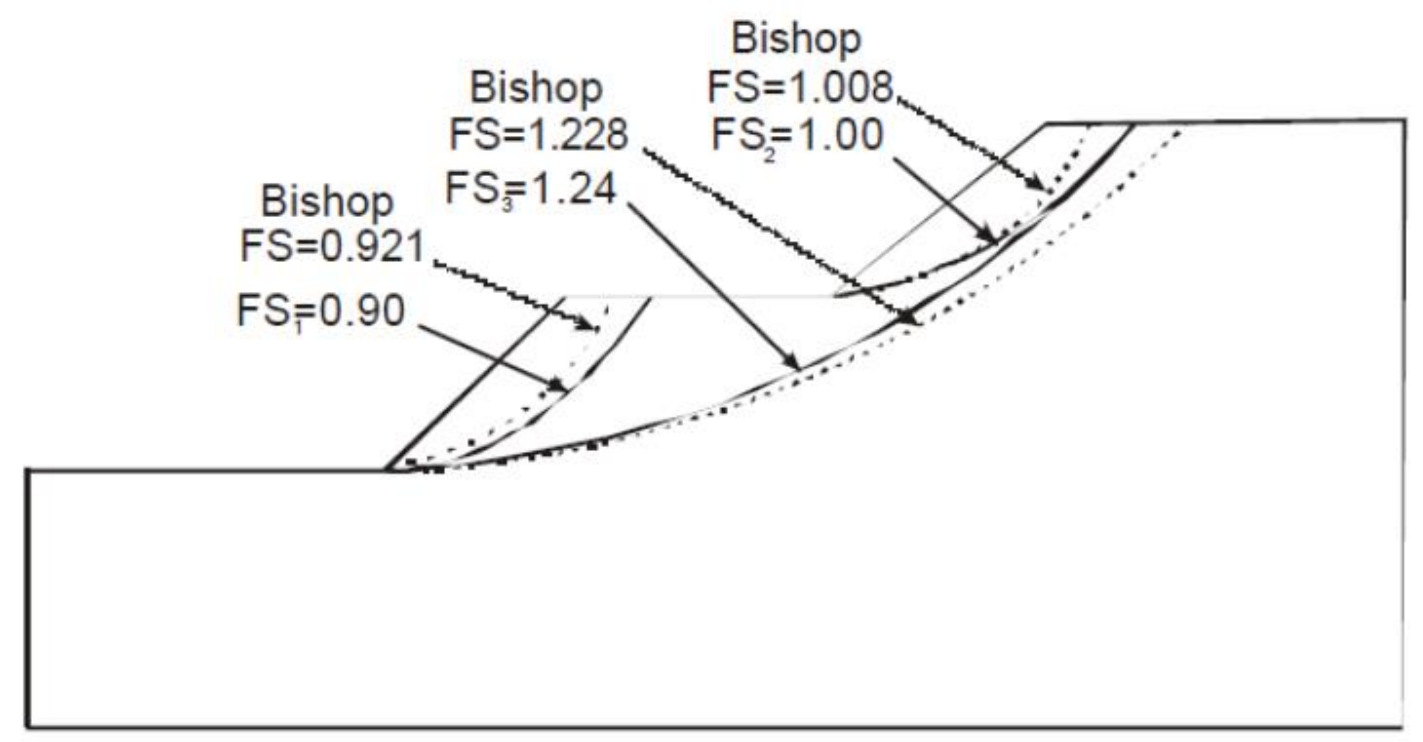

Figure 1. Factor of safety comparison between the LEM (FS) and the SSR (FS1) [18].

\section{Stability analysis methods}

Theoretical study and practical experience show that surface mine slopes typically experience four stages of drilling completion to collapse according to Mohr Columb, shear criteria: elastic stage, nonlinear deformation stage, creep deformation stage, and decay stage. For rock slopes, this means a large reduction in stability [4].

Most numerical methods used to solve rock engineering problems can be categorized into three main groups:

1. Continuous Methods: Finite Element Method (FEM). Boundary Element Method (BEM) and Finite Difference Method (FDM).

2. Discontinuous Methods: Distinct Element Method (DEM) and Batch Deformation Method (DDA).

3. Two-purpose (hybrid) methods: FEM/BEM hybrid, BEM/DEM hybrid, FEM/DEM hybrid and other hybrid methods (two-purpose, hybrid) [2].

Slope stability is traditionally estimated using twodimensional limit equilibrium (LEM) methods. However, these methods have many disadvantages and you may neglect some important factors. Due to the rapid development of computer computing efficiency, several numerical methods are gaining increasing popularity in slope sustainability engineering. Finite element method (FEM) and finite difference method (FDM) are often used for that purpose. Safety factor (FS) for slope may be calculated by reducing the shear strength of rock or soil during the steps until the slope fails. This method is called shear Strenght reduction (SSR) [5].
Limit equilibrium methods serve geotechnical engineering, and in particular gradient stability problems for decades.

Their basic characteristic is their simplicity and provenity, through decades of use, credit for geometry and relatively simple conditions. However, sustainability problems in large-scale open-pit mines often involve complexities that are not easily solved by extreme equilibrium methods. In this case, using numerical (more complex and powerful) methods such as finite element method (FEM) and finite difference method (FDM), it gives the engineer the opportunity to analyze the stability of the slope more comprehensively. The main advantage of numerical methods is that it does not require any assumptions about the shape, direction and location of slip surfaces: failure occurs "naturally" through areas where soil shear strength is unable to maintain the shear stresses applied on them.

In addition, numerical models are able to produce stress-strain distribution (deformation response), which may be of very important importance for strong interpretation of slope behavior, positioning and analysis of quite complex geometry, simulation of pit drilling stages and groundwater level positioning [1].

\section{Static, quasi-static, and dynamic analysis}

Three types of numerical stability analysis can be performed: static, quasi-static and dynamic [6]. However, it should be noted that quasi-static analysis is a very conservative approach [7]. The FS estimated by SSR with the FS obtained from Flenius, Bishop, 
Morgenstern-Price and Janbu can be compared through the mentioned numerical methods [5].

Factors affecting stability, including adhesion, median friction angle, and tensile strength are effective factors on analysis.

The results of the analysis show that with increasing adhesion, the slope failure mode changes from shallow slip to deep slip, while the slope of the slip plate slows down and the slip volume becomes larger; It finds and the slip surface is turned away from the slope apex by increasing tensile strength [8].

The progress of mining operations in deeper zones usually causes numerous changes in stresses. These changes will lead to some failures and problems of un stability in different parts of the mine. It seems that the main parameters that affect the failure and instability of mine slopes. High groundwater pressure and the system of discontinuity (faults, seas, layer designs) are the pit walls. To overcome these problems, numerical analysis can be performed using a software such as Flac software.

To prepare input parameters for modeling, field studies (including discontinuity mapping, point load index test, and Schmidt hammer test) and laboratory tests (to determine pressure, shear and elastic constants) are needed. Then, the orientation of laboratory discontinuity and data is analyzed to determine the main structures and parameters of shear strength to determine the peat walls of modeling and safety factors. The results of numerical analysis should always be in good agreement with real observations in the mine, and the analyses performed using other methods [9].

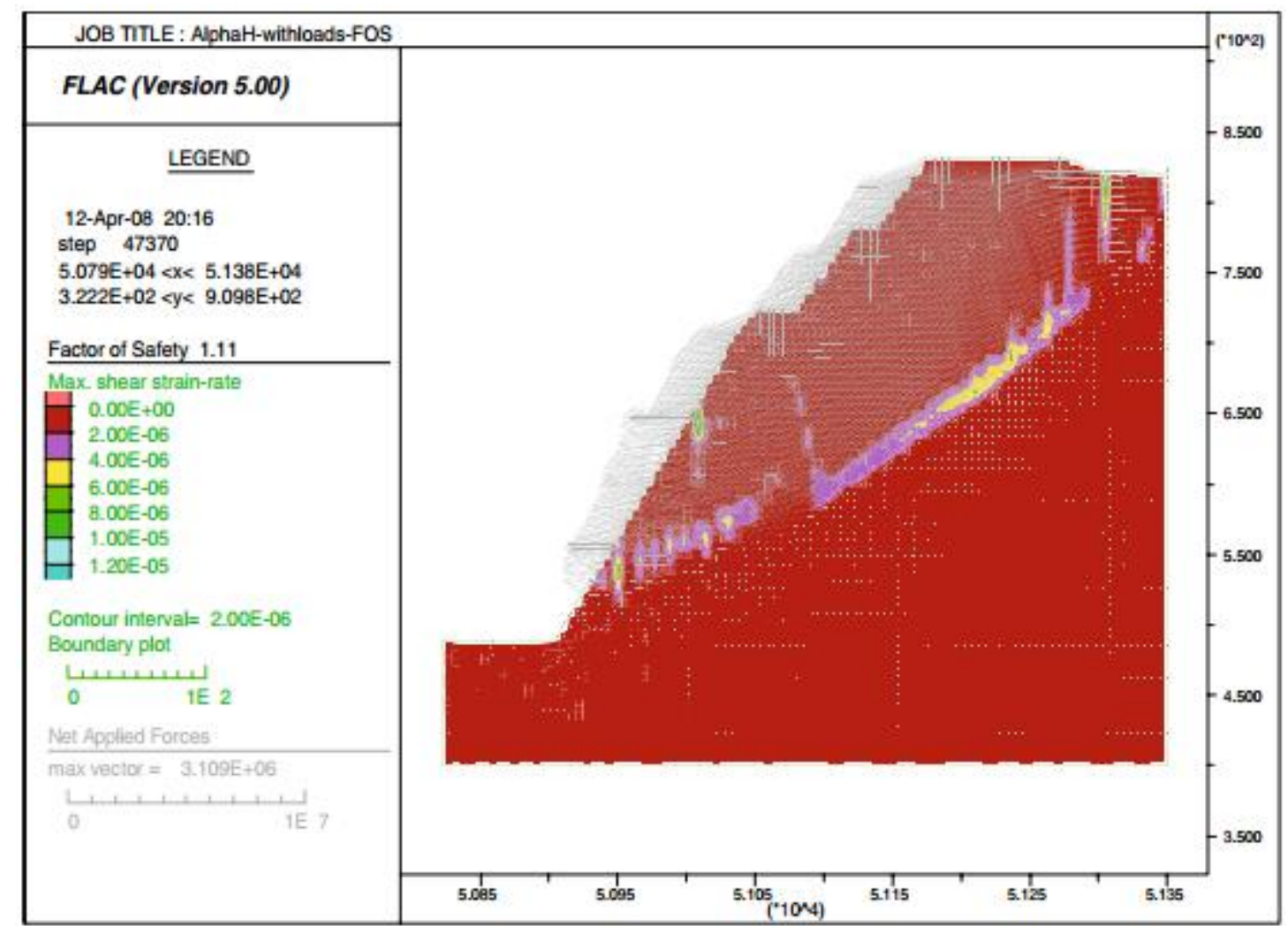

Figure 2. FOS plot for the slope using pseudo-static approach [7].

\section{Finite difference method}

The main difference between finite element method and finite difference is the explicit design of the implemented solution to solve a weak form of differential equations, otherwise these two methods are mathematically identical. In the method of Finite difference, the continuous environment is defined by a network of separate points in which displacements, speeds, and accelerations are calculated. By implementing an explicit solution in the method of Finite difference in processing time and memory required by avoiding solving large sets of equations is reduced. Linear modeling process with finite difference method is slower than finite element method. Therefore, the Finite difference method is more suitable for solving nonlinear problems, or for solving physical instability problems [2]. A sample of limited difference analysis can be seen in Figure 1. 


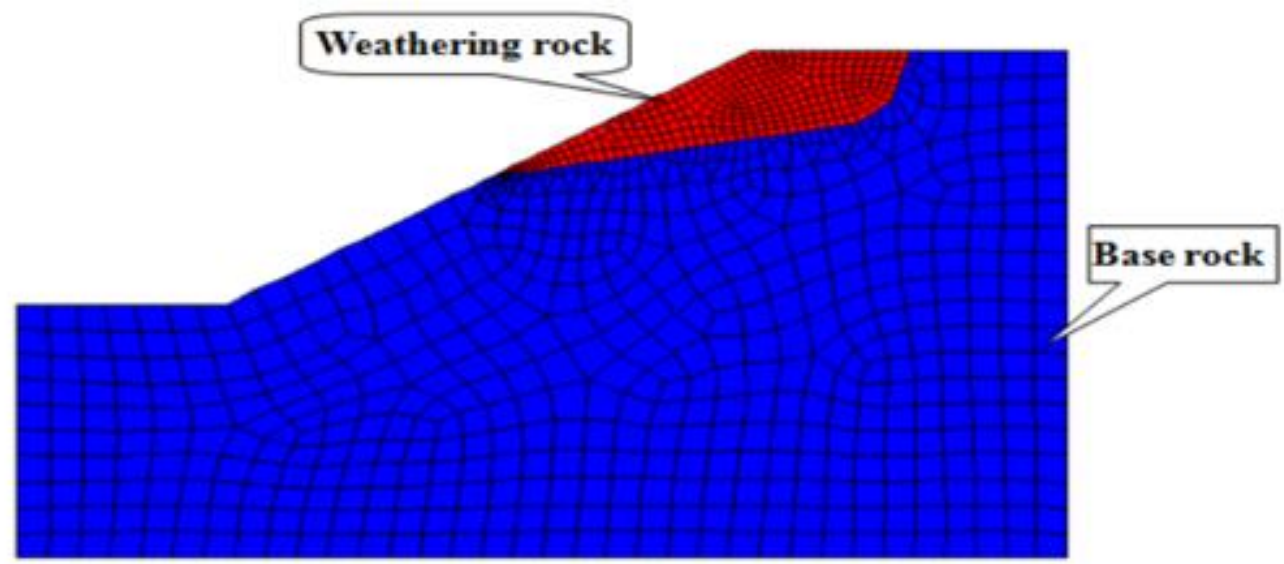

Figure 3. Sample of a mesh network in numerical modeling using FLAC3D software [10].

\section{FLAC software}

FLAC software is produced in three versions: $2 \mathrm{D}, 3 \mathrm{D}$ and Flac/Slope [16]. Itasca FLAC3D software has been widely used in the analysis of underground tunnels, open pit mines, and complex underground mines in terms of gravity, groundwater, and other factors. But there are some problems in building a complex numerical model using FLAC3D alone [4].

FLAC 3D is applied to create a model based on topography obtained from field measurements. According to the results of the analysis, some appropriate measures are suggested for tunnel slope strength [11]. In cases where a two-dimensional model does not accurately represent the shape of failure and complete behavior and incongruousness of the location, a 3D model is performed using FLAC3D software [12].

Changing properties of slope soil are carried out based on geological as well as geophysical (environmental resistance and noise) and geotechnical experiments carried out on the slope. 3D static determinant analysis is performed to determine the overall safety factor of the slope and to find the location of the critical failure level [13].

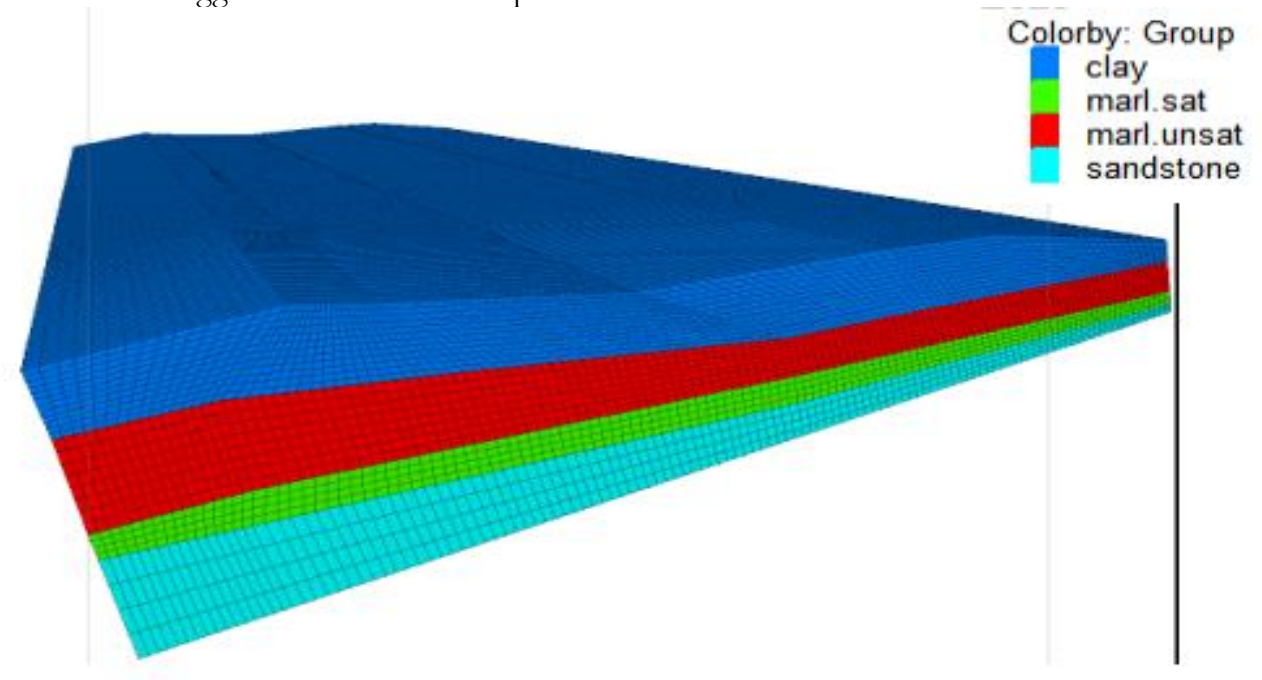

Figure 4. FLAC3D static model [12].

The two-dimensional FLAC is equipped with an integrated module to calculate the safety factor for gradient stability analysis. Shear resistance reduction method is used to determine the safety factor. Static analysis can be performed using integrated module in FLAC [6]. The two-dimensional flack is able to analyze a range of engineering problems such as homogeneous, heterogeneous slopes, multilayered amplitudes with
Poisson ratios, conditions and slope angles, different manganic pressure [14].

Flac code often applies to FS estimates for rock slopes or even laminated rocks. Flac is also widely used to evaluate the stability of soft rock slopes excavated by underground craters. Sometimes FLAC is even used to engineer gradient stability in combination with other methods. Babu \&amp; Bijoy (1999) shows examples of 
FLAC application associated with LEM. Wang et al. (2000) Offers flac usage facilities with Monte Carlo method.

The SSR technique is often used with FEM to solve quite complex problems such as estimating the stability of tilt reinforcement by candles [columns] or slope with horizontal drains. A good overview of FEM's application for slope stability engineering may be found in Fredlund \& Scoular (1999).

The advantages and disadvantages of SSR and LEM are presented in Jiang \& Magnan 1997, Griffiths \& Lane (1999). The majority of researchers prefer the use of
FEM or FDM to estimate FS domains [5]. This finite difference software is able to model the behavior of soil, stone or other materials that may be reached into submission or plastic flow. Re-analysis method is applicable using this software [15]. Flack uses conventional nomenclature in stress analysis programs such as finite element and finite difference for stress analysis.

The basic definitions states are displayed to explain the scientific terminology of flack in Figure 2 and the overall trend of analysis in Figure 3.

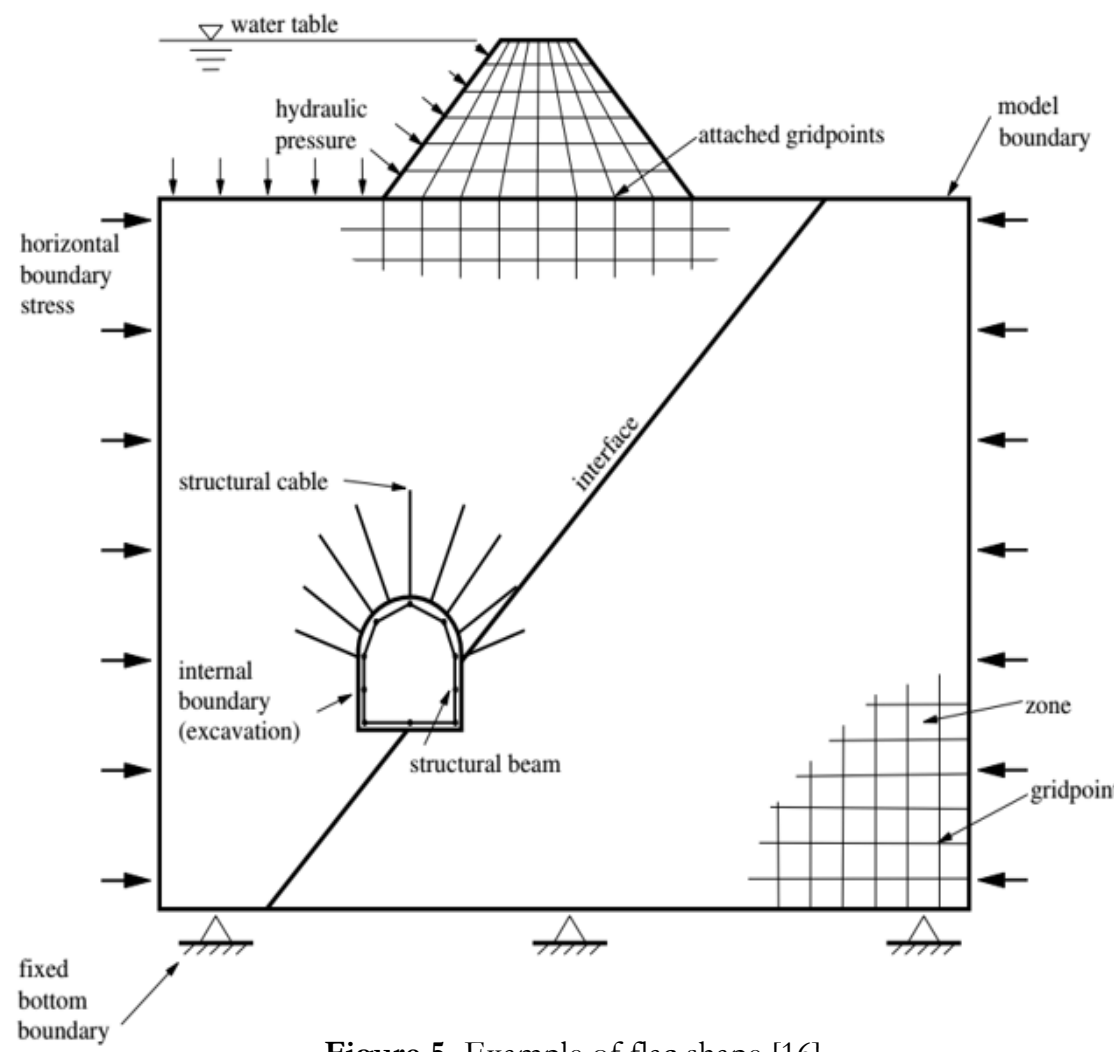

Figure 5. Example of flac shape [16].

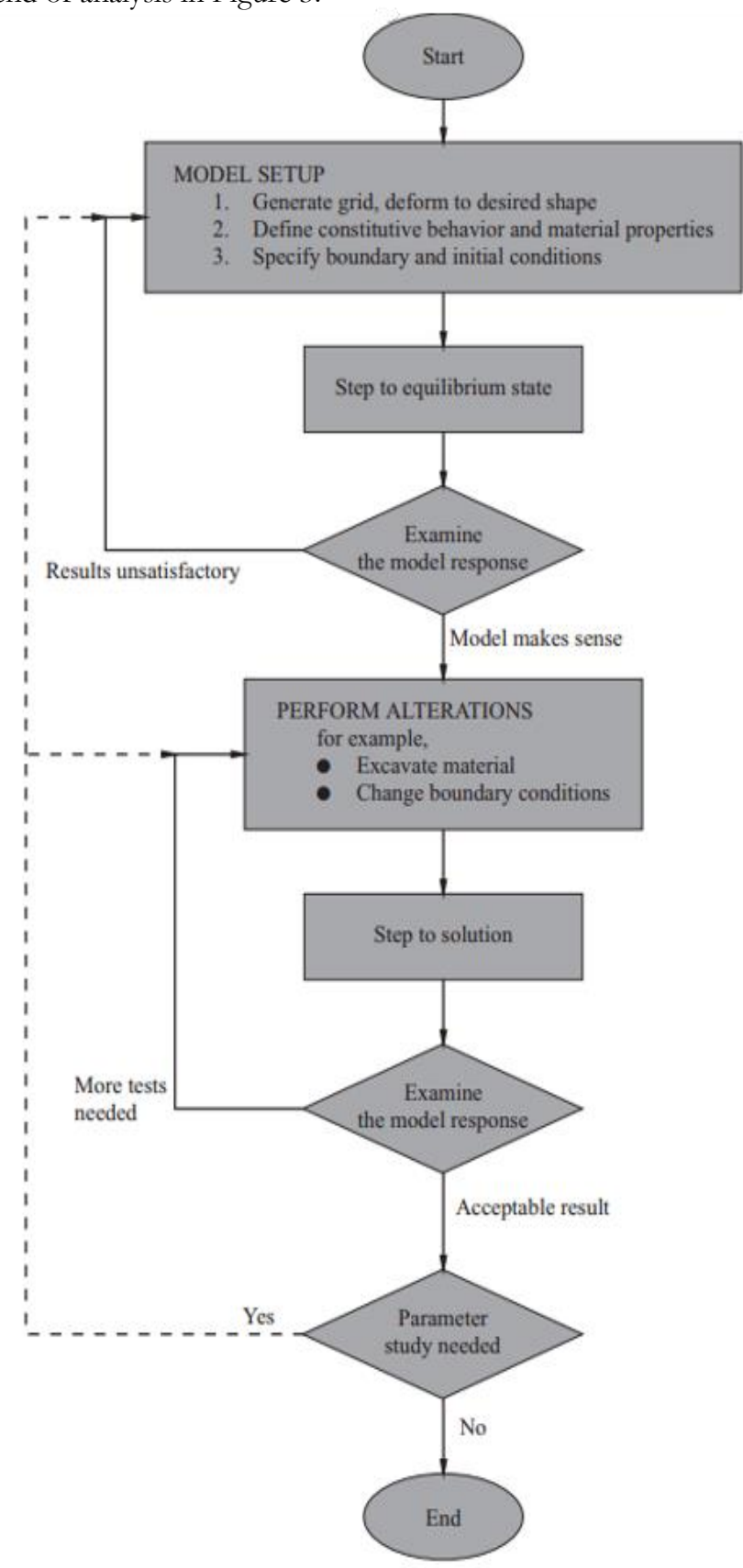

Figure 6. General Analysis Procedure in FLAC Software [16]. 


\section{Case study}

In this presentation, we have analyzed the stability of the proposed final wall for Iron Plasri Mine in Sangan area according to its exploratory and executive information. According to the discoveries, the depth of the mineral is about 66 meters, which according to the dimensions of the machines used and the technical specifications of the mineral presented in Table 1 , has been designed and analyzed the stability of this wall. The proposed dimensions for this wall are 6 stairs with dimensions of 11 to 11 .

Table 1

Values related to adhesion, internal friction angle and specific gravity obtained from return analysis [17].

\begin{tabular}{ll}
\hline Amount & Parameter \\
\hline$r, r_{0}$ & Cohension $(\mathrm{kg} / \mathrm{cm} 2)$ \\
$\Sigma \varepsilon$ & Internal friction angle (degree) \\
$r, Y)$ & Specific gravity $(\mathrm{g} / \mathrm{cm} 3)$ \\
\hline
\end{tabular}

The boundary conditions used in this analysis are as follows: at the base of the network both the displacement ' $x$ ' and ' $y$ ' constant; on either side of the fixed ' $x$ ' displacement network; The slope is allowed to move free in both directions.
According to the results of the analysis presented in images $4,5,6,7$, it can be observed that the proposed wall has the necessary stability during the extraction period.

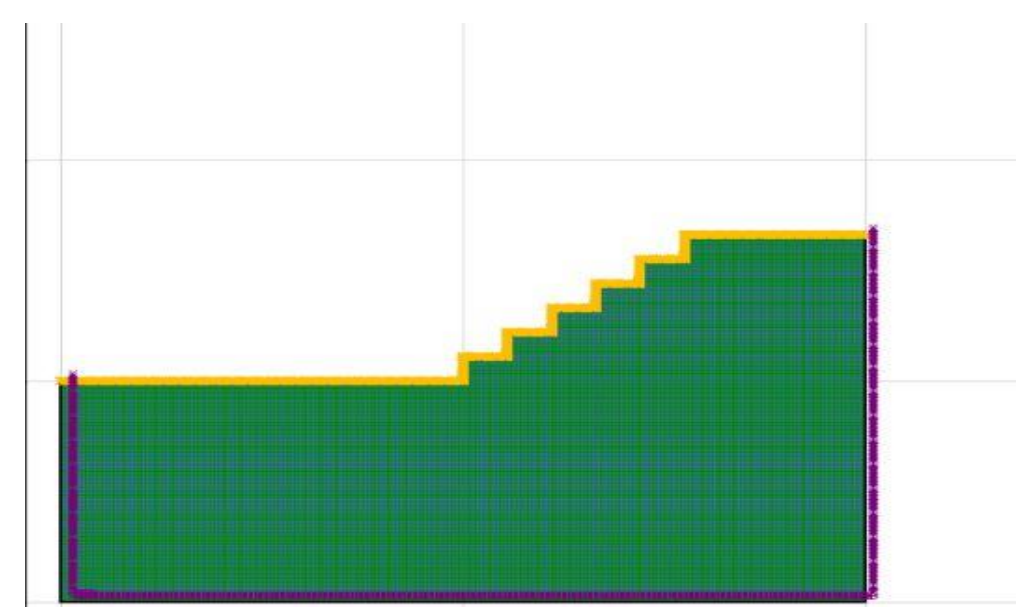

Image 4. Initial view of the design.

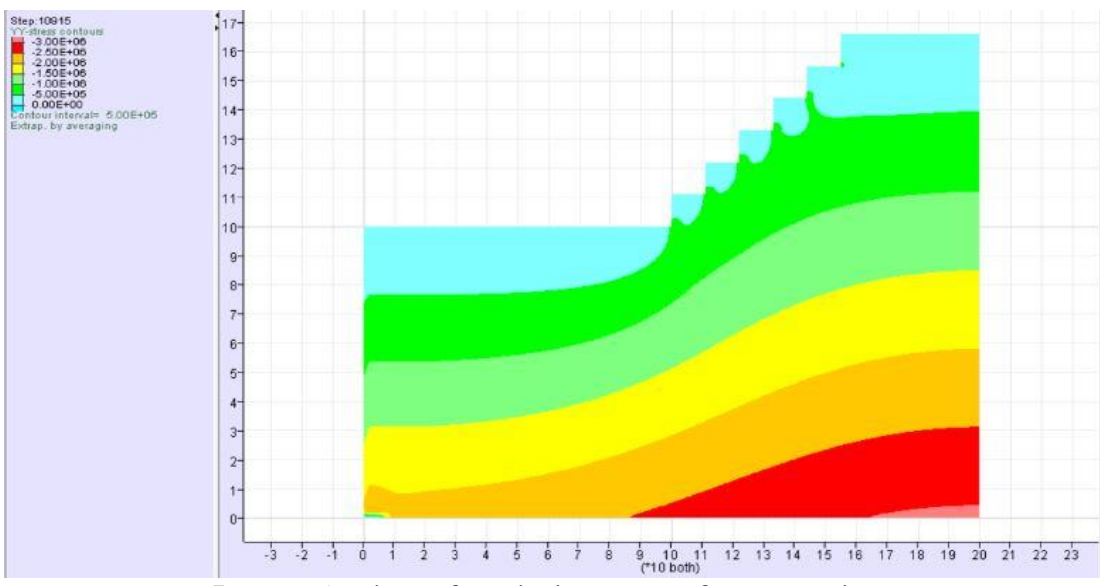

Image 5. View of vertical stresses after extraction. 


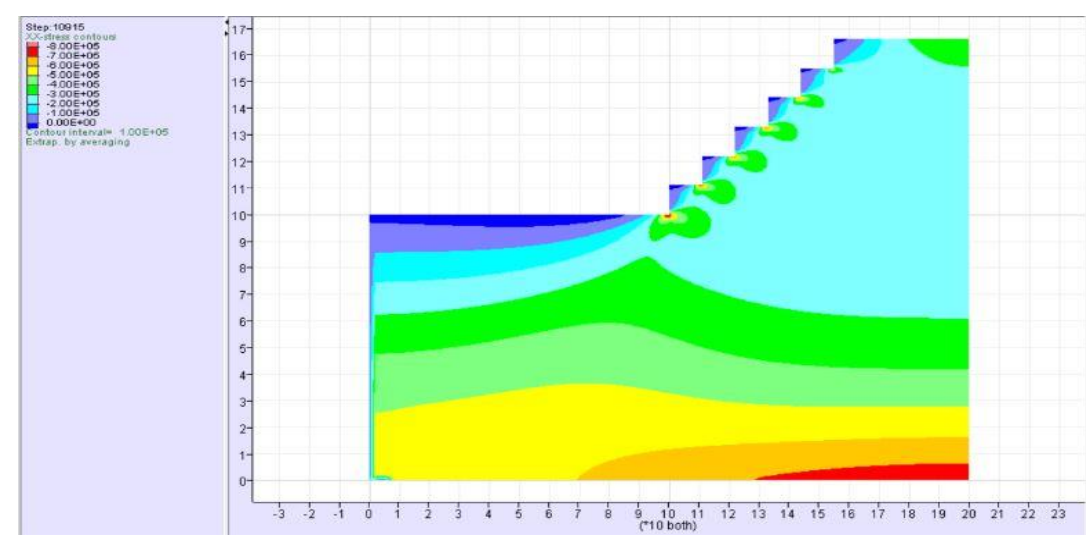

Image 6. View horizontal stresses after extraction.

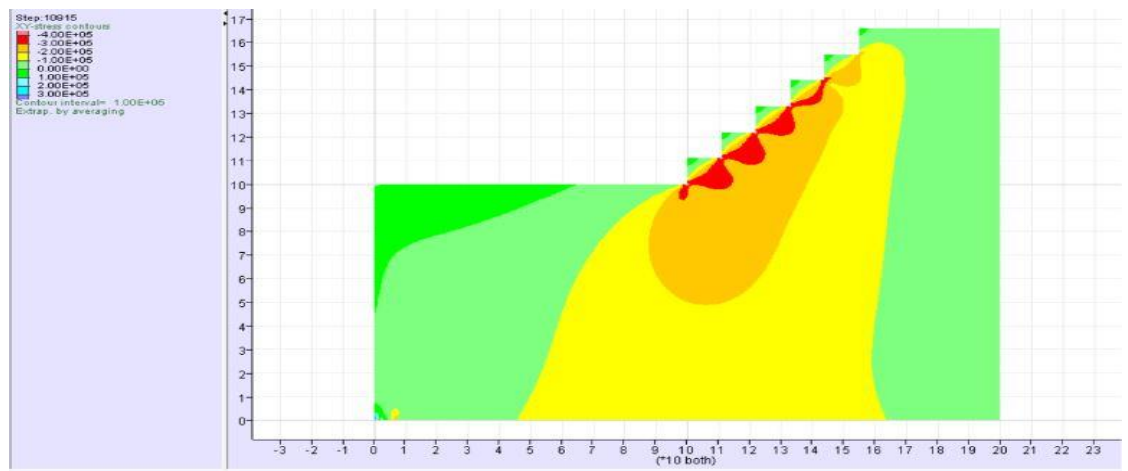

Image 7. View of horizontal and vertical stresses.

\section{Conclusion}

Due to the increasing expansion of mineral and construction structures and cavities and the weaknesses of traditional structural stability analysis methods such as partial analysis method, the use of numerical methods in structural analysis is inevitable. One of these methods is the limited difference method which has been used in FLAC software. The results of final wall analysis by this software indicate the stability of this wall in static conditions and the absence of the effect of surface and groundwater and dynamic loads and discontinuity, each of which can be analyzed separately or at the same time.

\section{References}

1. Deliveris AV, Zevgolis IE, Koukouzas NC. Numerical modeling of slope stability in open pit lignite mines: A comparative study. Bull Geol Soc Greece, 2016; 50.

2. Sherizadeh T. Assessment of roof stability in a room and pillar coal mine in the US using three dimensional distinct element method (Doctor of Philosophy). 2016; http://hdl.handle.net/10150/579111
3. Reale C, Xue J, Pan Z, Gavin K. Deterministic and probabilistic multi-modal analysis of slope stability. Comput Geotech. 2015; 66: 172-179.

4. Fan W, Cao R, Zhang K, Li K, Chen C. Stability assessment and optimization design of lakeside openpit slope considering fluid-solid coupling effect. Math Probl Eng. 2015.

5. Cala M, Flisiak J. Slope stability analysis with FLAC and limit equilibrium methods. FLAC and Numerical Modelling in Geomechanics, AA Balkema Publishers, 2001; 111-114.

6. Ghobrial F, Karray M, Delisle MC, Ledoux C. Development of spectral pseudo-static method for dynamic clayey slope stability analysis. 2015.

7. Latha GM, Garaga A. Seismic stability analysis of a Himalayan rock slope. Rock Mech Rock Eng. 2010; 43(6): 831-843.

8. Lin Hang, Cao Ping, Gong Feng-qiang, Li Jiang-teng, Gui Yi-lin. Directly searching method for slip plane and its influential factors based on critical state of slope. J Centr S Univ Tech. 2009; 16: 131-135.

9. Bagherian A, Shahriar K. Slope stability at Gol-EGohar iron mine. 18"' International Mining Congress and Exbibition of Turkey-IMCET. 2003. 
10. Wu YX. Dynamic stability analysis of weathering rock slope by strength reduction method. Elect J Geotech Eng. 2016.

11. Jin-feng Z, Yu S. Stability analysis of tunnel slope considering dynamic load and strength subtraction method.

12. Matar T, Chehade FH, Harb J, Rahhal M, Massih DYA, Abdallah C, Sursock A. Static and dynamic analyses of Dahr El Baidar slope. 2015.

13. Neaimeh M, Azar R, Hmaymes R, Nasr G, Massih A, Youssef D, Jongmans D. Effect of the soil spatial variability on the static and dynamic stability analysis of a Lebanese slope. 2013.

14. Stianson JR, Chan D, Fredlund DG. Comparing slope stability analysis based on linear elastic or elastoplastic stresses using dynamic programming techniques. In Proc;; 57th Canadian Geotechnical Conf. 2004; 23-30.

15. Dadashzadeh Sayar A, Khalilpasha MH. Using extensometer as a monitoring system, case study: Taloun Pilot Tunnel in Tehran - North of Iran Freeway. J Basic Appl Sci Res. 2012; 2(2): 1696-1700.

16. Itasca. FLAC7 manual. 2020; https://www.itascacg.com

17. Amiri O. Evaluation of stability of walls of Sangan Plasri Iron Ore Mines (MSc Thesis). University of Birjand, Birjand, Iran. 2016.

18. Ureel S, Momayez M. An investigation of the limit equilibrium method and numerical modeling for rock slope stability analysis. Rock Mech App Civil Min Petrol Eng. 2014; 218-227.

\section{SJIS}

Copyright: (C) 2021 The Author(s); This is an open-access article distributed under the terms of the Creative Commons Attribution License (http://creativecommons.org/licenses/by/4.0), which permits unrestricted use, distribution, and reproduction in any medium, provided the original work is properly cited.

Citation: Vaze Mobaraki J. Stability Analysis of Mineral Structures using FLAC Software. SJIS, 2021; 3(1): 1-8. 